\title{
First report of seroprevalence of Toxoplasma gondii infection in sheep in Pomerania, northern Poland
}

\author{
Lucyna Holec-Gąsior', Bartosz Dominiak-Górski², Józef Kur ${ }^{1}$ \\ ${ }^{1}$ Department of Molecular Biotechnology and Microbiology, Faculty of Chemistry, Gdańsk University of Technology, Poland \\ 2 Veterinary Hygiene Station, Gdańsk, Poland
}

Holec-Gąsior L, Dominiak-Górski B, Kur J. First report of seroprevalence of Toxoplasma gondii infection in sheep in Pomerania, northern Poland. Ann Agric Environ Med. 2015; 22(4): 604-607. doi: 10.5604/12321966.1185761

\begin{abstract}
Introduction and objective. Toxoplasmosis is parasitic disease which has economic relevance for both veterinary and human medicine. In sheep, toxoplasmosis is a major cause of abortion and can thus cause reproductive problems. The current study aimed to determine the occurrence of anti-Toxoplasma gondii IgG antibodies in sheep from 13 districts of northern Poland and thereby obtain actual data about T. gondii seroprevalence in this population of animals.

Materials and methods. Blood samples from 1,646 animals from 99 herds were collected, and an in-house enzymelinked immunosorbent assay (ELISA) based on native Toxoplasma lysate antigen (TLA) was used for serological testing. The diagnostic sensitivity of diagnostic test used in this study was $98.6 \%$, and specificity $94.9 \%$ for the group of 113 sheep sera (74 seropositive and 39 seronegative) previously characterized by using an commercial agglutination test.

Results. Antibodies against T. gondii were found in 921 (55.9\%) of all tested animals. The percentage of infected sheep was the highest (67.6\%) for older animals (>6 years), whereas for younger ones it was significantly lower $(50.1 \%-57.2 \%$ for 1-5-year-old animals, respectively). Furthermore, a higher percentage of seropositive animals was noted among males (63\%) than females (55.5\%). The results also showed that the size of the herd is not a factor which may affect the seroprevalence of $T$. gondii infection in the examined population of sheep.

Conclusion. The results of this study indicate that $T$. gondii infection in sheep from region of northern Poland is relatively high, and consumption of ovine meat and milk can be regarded as a significant source of infection for humans.
\end{abstract}

Key words

sheep, Toxoplasma gondii, toxoplasmosis, ELISA, seroprevalence, northern Poland

\section{INTRODUCTION}

Toxoplasma gondii (phylum Apicomplexa) is an obligate intracellular coccidian protozoan parasite that infects all warm-blooded animals, including mammals, birds and humans, and has substantial medical and veterinary significance [1]. The parasite has a worldwide distribution and is mainly transmitted by food contaminated by oocysts excreted in the faeces of infected cat, by undercooked or raw meat (mainly pork and lamb) containing tissue cysts, or unpasteurized milk of infected animals, and transplacentally [2]. Although the invasion is mostly asymptomatic and selflimiting in immunocompetent individuals, it may lead to a life threatening disease in humans with impaired immune response or immune system immaturity. Furthermore, intrauterine transmission of the parasite from the mother to the foetus during gestation can result in severe foetal and neonatal complications. Toxoplasmosis is also an economically important disease of livestock, especially sheep. T. gondii infection in sheep is distributed worldwide, with seroprevalence of $20-91 \%$ in different countries [3]. These differences may occur due to the study area, associated factors, and criteria for animal selection, as well as the technique used for the epidemiological studies. Ovine toxoplasmosis may

Address for correspondence: Lucyna Holec-Gąsior, Department of Molecular Biotechnology and Microbiology, Faculty of Chemistry, Gdańsk University of Technology, Narutowicza 11/12, 80-233 Gdańsk, Poland

E-mail: holec@pg.gda.pl

Received: 30 November 2013; accepted: 26 March 2014 give rise to various disorders and lead to lower reproductive yields, especially during pregnancy [4]. Already in the 1950s, T. gondii was reported as a significant cause of abortion in this population of animals [5]. In 1987, Blewett and Trees [6] suggested that the T. gondii parasite may be responsible for $1-2 \%$ of neonatal losses annually. Thus, these losses may translate to over 1.5 million lambs lost in Europe per year, representing a significant loss to producers and national economies [7]. In addition, the tissue cysts of T. gondii in meat of infected sheep are an important source of infection for humans [1].

The great importance of T. gondii as a causative agent of zoonosis indicate the need for epidemiological studies in animals that can be used as a source of food. In Poland, T. gondii infection is relatively widely prevalent in swine and cattle populations $[8,9,10,11,12]$. However, the presence of infection in the sheep population is scarcely documented. Considering the importance of toxoplasmosis in sheep reproduction and the lack of epidemiological information of ovine toxoplasmosis in Poland, the presented study aimed to determine the prevalence of $T$. gondii infection in sheep and the probable role of lamb consumption in human toxoplasmosis.

\section{MATERIALS AND METHOD}

Study area and serum samples. Investigations were carried out in 13 districts in northern Poland (Fig. 1). A total of 1,646 


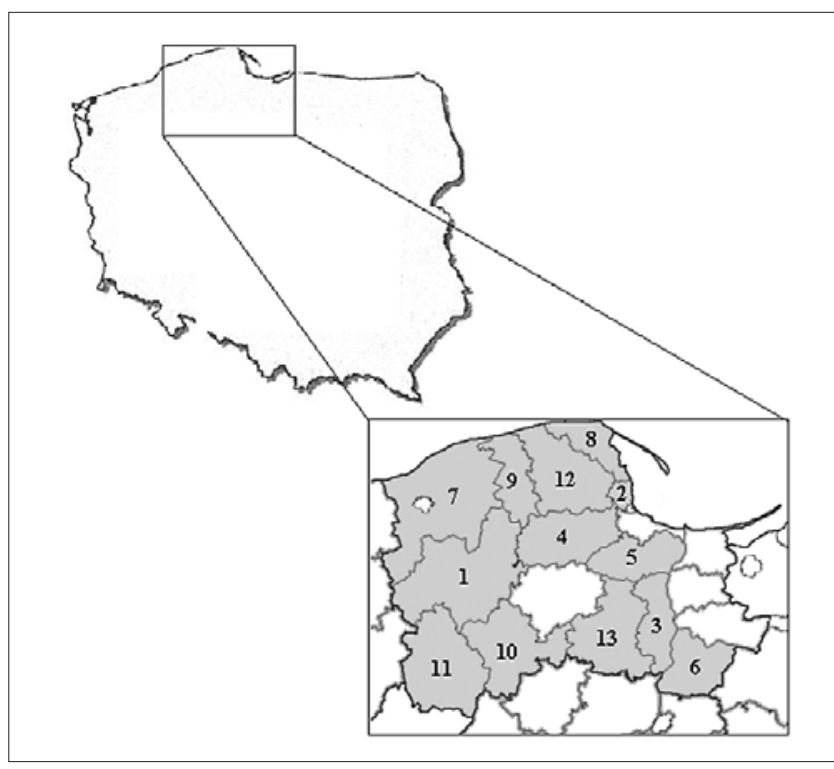

Figure 1. Sampled areas in Pomerania (grey, 1-13): 1) Bytowski, 2) Gdynia 3) Tczewski, 4) Kartuski, 5) Gdański, 6) Kwidzyński, 7) Słupski, 8) Pucki, 9) Lęborski, 10) Chojnicki, 11) Człuchowski, 12) Wejherowski, 13) Starogardzki

blood samples were collected from sheep of various ages (1-9 years; mean age 3.014 \pm 1.834 ), most of them females $(94 \%)$. Next, these samples were centrifuged and sera stored at $-20^{\circ} \mathrm{C}$ until assayed by IgG ELISA technique. The tested animals came from different farms (small or large and automated). The largest group of examined farms (70 out of 99) had herds of more than 20 head of sheep. Less than one-third of examined farms (26 out of 99) had more head of sheep (21-60 animals); however, the largest (more than 60 head of sheep), represented only $3.03 \%$ of all farms (3 out of 99 ).

In order to determine the cut-off value of the in-house IgG ELISA assay, a group of 20 control sheep sera previously characterized (seronegative for T. gondii and seropositive for Neospora caninum), collected in New Zealand, was used. This group consisted of sera for which negative results for specific anti-T. gondii antibodies were obtained with the use of agglutination test (Toxo-Screen DA, BioMérieux), whereas the positive results for specific anti-N. caninum antibodies were confirmed with the use of a commercially available competitive-inhibition enzyme-linked immunosorbent assay (cELISA) (VMRD, Inc.), and an immunofluorescence test (IFAT), using cut-off point of 1:50 [13], and as antigen, tachyzoites of $N$. caninum (Nc-1 strain), maintained by continuous passages in culture of VERO cells.

Furthermore, to assess the specificity and sensitivity of the in-house IgG ELISA assay used for epidemiological studies, a pool of previously characterized sheep serum samples was applied. A total of 113 sera were analyzed and divided into 2 groups in accordance with the results obtained using commercial tests (Toxo-Screen DA, BioMérieux): group I (IgG anti-T. gondii positive) - 74 sera from infected animals, and group II (IgG anti-T. gondii negative) - 39 sera from seronegative animals.

Serological examinations. The preparation of TLA has been described previously [8, 9]. MaxiSorp multiwells plates (Nunc, Denmark) were coated with $0.1 \mathrm{ml}$ TLA at the final concentration of $1 \mu \mathrm{g} / \mathrm{ml}$ in a coating buffer $(0.05$ $\mathrm{M}$ carbonate buffer, $\mathrm{pH}$ 9.6). The plates were then incubated overnight at $4^{\circ} \mathrm{C}$, followed by washing 3 times in PBS- $0,1 \%$ Triton X-100, and blocked for $2 \mathrm{~h}$ at $37^{\circ} \mathrm{C}$ in blocking solution ( $1 \%$ bovine serum albumin, $0,5 \%$ Triton X-100 in PBS). After washing, the plates were incubated for $1 \mathrm{~h}$ at $37^{\circ} \mathrm{C}$ with sheep sera diluted 1:100 in blocking solution. Next, the plates were washed 3 times with washing buffer and incubated with anti-sheep IgG peroxidase-labeled conjugates (Sigma) diluted 1:8,000 in blocking solution for $1 \mathrm{~h}$ at $37^{\circ} \mathrm{C}$. Then, o-phenylenediamine dihydrochloride (Sigma) chromogenic substrate was added. After $30 \mathrm{~min}$ at $37^{\circ} \mathrm{C}$ incubation in darkness, the reaction was stopped by adding $2 \mathrm{M}$ sulfuric acid. OD was measured at $490 \mathrm{~nm}$ using a microtiter plate reader (Multiscan FC; Thermo Scientific).

Each serum sample was examined twice and the results determined for each serum by calculating the mean value of the optical density (OD) reading for duplicate wells. Reference sera (positive and negative from groups I and II) on each ELISA plate were used in all experiments as controls.

Statistical analysis. The data were analyzed by chi-square $\left(\chi^{2}\right)$ test using the Microsoft Excel 2007 programme.

\section{RESULTS}

The pool of 1,646 sheep serum samples was examined for the presence of anti-T. gondii immunoglobulin G (IgG) antibodies using in-house enzyme-linked immunosorbent assay (ELISA), based on a native T. gondii antigen. The cut-off value was set as the mean value obtained for 20 seronegative serum samples from the control group plus 2 standard deviations, resulting in 0.474 . A positive result of the IgG ELISA test was regarded as any absorbance value higher than the calculated value of the cut-off. The sensitivity and specificity of the IgG ELISA test used in this study was estimated using a pool of 73 seropositive sera (group I) and 39 seronegative sera (group II) from sheep. One serum samples from group I reacted below the cut-off value, resulting in a sensitivity of $98.6 \%$, whereas for group II sera, 2 results above the cut-off were obtained (specificity 94.9\%). Therefore, the accuracy of the test used in this study was estimated as $97.3 \%$.

The mean absorbance of IgG ELISA obtained for all seropositive serum samples $(921$ out of 1,646 ) was 0.794 (range 0.479-1.891), whereas for all seronegative sera (425 out of 1646) -0.338 (range $0.114-0.470$ ). The prevalence of T. gondii infection in each district ranged from $30 \%-100 \%$ (Tab. 1). The statistical differences between the seroprevalence among the districts were also found $\left(\chi^{2}=58.726 ; \mathrm{p}<0.001\right)$. Seroprevalence in the examined animals increased progressively with age (Tab. 2), and the prevalence of T. gondii infection was significantly higher in older sheep ( $>6$ years) than in animals aged less than 1.5 years. Additionally, the presented study did not find any influence of the size of a herd of sheep on the percentage of T. gondii infected animals. For both small herds of less than 20 head of sheep, as well as for larger herds, the percentage of infected animals was above $55 \%$ (Tab. 2). Furthermore, a higher percentage of seropositive animals was observed among males than females. 
Table 1. Seroprevalence of T. gondii infection among sheep in Pomerania, northern Poland (13 districts)

\begin{tabular}{lccc}
\hline Districts & $\begin{array}{c}\text { No. of examined } \\
\text { samples }\end{array}$ & $\begin{array}{c}\text { No. of positive } \\
\text { samples }\end{array}$ & Seroprevalence (\%) \\
\hline Bytowski & 620 & 319 & 51.5 \\
\hline Gdynia & 50 & 38 & 76.0 \\
\hline Tczewski & 81 & 53 & 65.4 \\
\hline Kartuski & 385 & 215 & 55.8 \\
\hline Gdański & 46 & 26 & 56.5 \\
\hline Kwidzyński & 13 & 13 & 100 \\
\hline Słupski & 10 & 3 & 30.0 \\
\hline Pucki & 57 & 19 & 33.3 \\
\hline Lęborski & 78 & 51 & 65.4 \\
\hline Chojnicki & 113 & 82 & 72.6 \\
\hline Człuchowski & 40 & 28 & 70.0 \\
\hline Wejherowski & 141 & 70 & 49.6 \\
\hline Starogardzki & 12 & 4 & 30.0 \\
\hline Total & 1,646 & 921 & 55.9 \\
\hline
\end{tabular}

$\chi^{2}=58.726, p<0.001$

Table 2. Multivariate analysis for risk factors associated or not with infection caused by T. gondii in sheep from Pomerania in northern Poland

\begin{tabular}{|c|c|c|c|c|c|}
\hline \multirow[t]{2}{*}{ Variable } & \multirow[t]{2}{*}{ Category } & \multicolumn{2}{|c|}{$\begin{array}{l}\text { Total No. of } \\
\text { sheep }\end{array}$} & \multicolumn{2}{|c|}{$\begin{array}{c}\text { No. of sheep } \\
\text { with } T \text {. gondii } \\
\text { antibodies }\end{array}$} \\
\hline & & $\mathrm{n}$ & $\%$ & $\mathrm{n}$ & $\%$ \\
\hline \multirow{4}{*}{ Age } & $1-1.5$ year & 433 & 26.3 & 217 & 50.1 \\
\hline & $2-3$ years & 656 & 39.9 & 357 & 54.4 \\
\hline & $4-5$ years & 446 & 27.1 & 255 & 57.2 \\
\hline & $6-11$ years & 111 & 6.7 & 75 & 67.6 \\
\hline \multirow{2}{*}{ Gender } & females & 1554 & 94.4 & 863 & 55.5 \\
\hline & males & 92 & 5.6 & 58 & 63.0 \\
\hline \multirow{3}{*}{ Size of herd } & 1-20 sheep (70 herds) & 517 & 31.4 & 294 & 56.9 \\
\hline & $21-60$ sheep (26 herds) & 840 & 51.0 & 467 & 55.6 \\
\hline & more than 60 sheep ( 3 herds) & 289 & 17.6 & 160 & 55.4 \\
\hline
\end{tabular}

\section{DISCUSSION}

Sheep are highly susceptible to infections with T. gondii and may play a major role in the transmission of toxoplasmosis to humans. Furthermore, ovine toxoplasmosis has important veterinary implications because it is a significant cause of foetal loss in sheep worldwide. Considering the strong relevance of ovine toxoplasmosis for human health is very important to perform epidemiological studies which show the seroprevalence of this infection in the sheep population.

In the current study, the occurrence of antibodies against T. gondii in 1,646 sheep from northern Poland was investigated by the IgG ELISA test developed in our laboratory. In-house IgG ELISA assay was selected for epidemiological studies because this serodiagnostic method is a sensitive test that is able to detect low antibody titers even in recent infections; therefore, this technique is extremely efficient for the detection of IgG antibodies against T. gondii in animals. An IgG ELISA test based on TLA preparation was also previously used in epidemiological studies of the population of pigs and cattle $[8,9]$. The seroprevalence of toxoplasmosis in the total sheep population examined in this study was $55.9 \%$; thus, specific antibodies against $T$. gondii were found in 921 sera from the 1,646 tested samples. The literature date about the seroprevalence of toxoplasmosis among the sheep population in Poland are scarce.

To the best of the knowledge of the authors of the presented study, this is the first report about the occurrence of anti-T. gondii IgG antibodies in sheep in the Pomeranian Province of northern Poland, which also includes the largest population of animals that have been studied in our country. Furthermore, the prevalence obtained in this study is very similar to that reported earlier by Michalski and PlattSamoraj [14] and by Górecki et al. [15] in Poland. These authors found the specific antibodies for T. gondii in 55\% $(11 / 20)[14]$ and $53.65 \%(22 / 41)[15,16]$ of investigated sheep with the use of direct agglutination assay (Toxo-Screen DA, bioMérieux) and indirect fluorescent antibody test (IFAT), respectively. A similarly high percentage of infected animals has been observed in other European countries, e.g. Bulgaria - 48.2\% [17], Czech Republic - 59\% [18], France - 65.6\% [19] and Lithuania $-42.1 \%$ [20]. This high percentage of serumreactive sheep to $T$. gondii could be related to environmental contamination by the parasite. In Poland, most sheep breeding on farms is traditional, and the animals have direct contact with cats. Oocyst-contaminated pastures, fodder, and drinking water are regarded as potential sources of postnatal infection in sheep. Therefore, it is important to know which feeding practices pose an increased infection risk. Unfortunately, in this study, information about feeding practices of the examined sheep population was not available. However, this information would be very valuable.

The results of this study also show that the prevalence of toxoplasmosis among sheep depends on the age and gender of the animals. A progressive increase in anti-T. gondii antibodies with age $(50.1 \%-67.6 \%$ for the annual sheep and those older than 6 years, respectively) suggests a continuous exposure to the organisms in the environment. Moreover, these results indicate that postnatal acquisition of infection is an important route of transmission of the parasite in sheep. In the case of the gender of the examined animals, it was found that the prevalence in males (63\%) was slightly higher than in females (55.5\%). However, these results may differ from actual seroprevalence because the male and female population consisted of a different number of animals. The group of males represented only $5.6 \%$ of the tested population of animals. Furthermore, according to some authors, females are considered a risk factor for toxoplasmosis due to hormonal and physiological differences $[21,22]$.

The presented study also found that the size of herd had no impact on the percentage of animals infected with T. gondii. A similar percentage of infected animals was observed in both small household farms with up to 20 pieces of sheep (56.9\%), as well as in larger herds (at a level above 55\%). These results therefore indicate that sheep are highly susceptible to infections with $T$. gondii.

In conclusion, according to the high percentage of seropositive sheep and the importance of the meat in transmission of toxoplasmosis to human, investigation of sheep and other domestic and meat production animals is indicated and necessary. The monitoring of T. gondii infection in animals destined for human consumption is a great challenge for human toxoplasmosis prevention. 
This study documents for the first time the epidemiology of T. gondii infection in sheep in the Pomeranian Region of northern Poland. Further studies are needed to elucidate the epidemiology in the whole country.

\section{Acknowledgements}

This study was financed by Grant No. IP2011 017571 within the science budget for 2012-2014. All sheep sera were provided by the Veterinary Hygiene Station in Gdansk, Poland, and the reference negative sera (control group of 20 samples) were kindly provided by Prof. M. Stankiewicz at Lincoln University, Christchurch, New Zealand.

\section{REFERENCES}

1. Tenter AM, Heckeroth AR, Weiss LM. Toxoplasma gondii: from animals to humans. Int J Parasitol. 2000; 30: 1217-1258.

2. Montoya JG, Liesenfeld O. Toxoplasmosis. Lancet. 2004; 363: 19651976.

3. Dubey JP. Toxoplasmosis in sheep - the last 20 years. Vet Parasitol. 2009; 163: 1-14

4. Dubey JP, Kirkbride CA. Toxoplasmosis and other causes of abortions in sheep from north central United States. J Am Vet Med Assoc. 1990; 196: $287-290$

5. Hartley W, Jebson JL, McFarlane D. New Zealand II type abortion in ewes. Aust Vet J. 1954; 30: 216-218.

6. Blewett DA, Trees AJ. The epidemiology of ovine toxoplasmosis with special respect to control. Br Vet J. 1987; 143: 128-135.

7. Innes EA, Bartley PM, Buxton D, Katzer F. Ovine toxoplasmosis. Parasitology. 2009; 136: 1887-1894.

8. Holec-Gąsior L, Kur J, Hiszczyńska-Sawicka E, Drapała D, DominiakGórski B, Pejsak Z. Application of recombinant antigen in serodiagnosis of swine toxoplasmosis and prevalence of Toxoplasma gondii infection among pigs in Poland. Pol J Vet Sci. 2010; 13: 457-464.
9. Holec-Gąsior L, Drapała D, Dominiak-Górski B, Kur J. Epidemiological study of Toxoplasma gondii infection among cattle in Northern Poland. Ann Agric Environ Med. 2013; 20: 653-656.

10. Sroka J. Seroepidemiology of toxoplasmosis in the Lublin region. Ann Agric Environ Med. 2001; 8: 25-31.

11. Sroka J, Zwoliński J, Dutkiewicz J. Seroprevalence of Toxoplasma gondii in farm and wild animals from the area of Lublin province. Bull Vet Inst Pulawy. 2007; 51: 535-540.

12. Sroka J, Wójcik-Fatla A, Szymańska J, Dutkiewicz J, Zając V, Zwoliński J. The occurrence of Toxoplasma gondii in people and animals from rural environment of Lublin region - estimate of potential role of water as a source of infection. Ann Agric Environ Med. 2010; 17: 125-132.

13. Helmick B, Otter A, McGarry J, Buxton D. Serological investigation of aborted sheep and pigs for infection by Neospora caninum. Res Vet Sci. 2002; 73:187-189.

14. Michalski M, Platt-Samoraj A. Ekstensywność inwazji Toxoplasma gondii u kóz i owiec z okolic Olsztyna. Med Wet. 2004: 60:70-71.

15. Górecki MT, Andrzejewska I, Steppa R. Prevalence of Toxoplasma gondii in sheep and goats. Med Wet. 2005; 61: 98-99.

16. Górecki MT, Andrzejewska I, Steppa R. Is order of voluntarily entrance to milking parlour related to Toxoplasma gondii infection in sheep - a brief note. Appl Anim Behav Sci. 2008; 110: 392-396.

17. Prelezov P, Koinarski V, Georgieva D. Seroprevalence of Toxoplasma gondii infection among sheep and goats in the Stara Zagora region. Bulgarian J Vet Med. 2008; 11: 113-119.

18. Bártová E, Sedlák K, Literák I. Toxoplasma gondii and Neospora caninum antibodies in sheep in the Czech Republic. Vet Parasitol. 2009; 161:131-132.

19. Dumètre A, Ajzenberg D, Rozette L, Mercier A, Dardé ML. Toxoplasma gondii infection in sheep from Haute-Vienne, France: seroprevalence and isolate genotyping by microsatellite analysis. Vet Parasitol. 2006; 142:376-379.

20. Stimbirys A, Bagdonas J, Gerulis G, Russo P. A serological study on the prevalence of Toxoplasma gondii in sheep of Lithuania. Pol J Vet Sci. 2007; 10: 83-87.

21. Alexander J, Stinson WH. Sex hormones and the course of parasitic infection. Parasitol Today. 1988; 4: 189-193.

22. Van Der Puije WNA, Bosompem KM, Canacoo EA, Wastling JM, Akanmori BD. The prevalence of anti-Toxoplasma gondii antibodies in Ghanaian sheep and goats. Acta Trop. 2000; 76: 21-26. 